\title{
Researching massive open online courses for language teaching and learning
}

\author{
Elena Martín-Monje \\ Universidad Nacional de Educación a Distancia (UNED), Spain (emartin@flog.uned.es) \\ Kate Borthwick \\ University of Southampton, United Kingdom (K.Borthwick@soton.ac.uk)
}

There has been an increasing interest in open educational resources, open practices, and open learning spaces in language teaching and learning in the last decade (Comas-Quinn \& Borthwick, 2015; Gimeno-Sanz, 2016) in which language massive open online courses (LMOOCs) have played a relevant role. Defined by Bárcena and Martín-Monje (2014: 1) as "dedicated Web-based online courses for second languages with unrestricted access and potentially unlimited participation", LMOOCs have experienced an exponential growth since their appearance in 2012 (Jitpaisarnwattana, Reinders \& Darasawang, 2019), with an unexpected boost due to the recent pandemic, which has led language learning to be in the top 10 subjects of interest in MOOCs (Shah, 2020).

MOOCs have caused a stir in the educational landscape, blurring the distinction between formal, non-formal, and informal education, and encouraging new models of content delivery, tuition, assessment, and accreditation. They have been heralded as a serious attempt to democratise higher education, enabling students around the world access to good-quality language learning resources (see, for instance, Mazoue, 2013). MOOCs are both learner centred and socially oriented, and focus on online social interaction and flexible multimodal resources (Bárcena, Read, Martín-Monje \& Castrillo, 2014). They eliminate potential problems such as registration fees and compulsory attendance but preserve the essential defining features of an academic course (i.e. syllabus, learning objectives, course materials, activities, teacher-student and student-student interaction, assessment, etc.). There is even the possibility of obtaining a certificate after completing the course, and in some cases participants obtain credits that are valid for further qualifications at university level.

Language MOOCs have been acknowledged to be an emergent and expanding research field (Godwin-Jones, 2014; Martín-Monje \& Bárcena, 2014; Panagiotidis, 2019), but have been recently identified by Gillespie (2020) as one of the less studied areas in computer-assisted language learning (CALL). Despite this lack of published research, Gillespie notes that "EUROCALL [the European Association for Computer Assisted Language Learning] has an LMOOC Special Interest Group, so there is clearly interest in this area" (p. 135) and advises researchers to pursue this endeavour.

A systematic review of the published literature in LMOOCs (Sallam, Martín-Monje \& Li, 2020) has revealed some interesting issues. The main common features of LMOOC design are (1) a robust set of communications for language learning, (2) short videos with linguistic and cultural content, and (3) assessment tools that are valid for heterogeneous cohorts. The main strengths of

\footnotetext{
Cite this article: Martín-Monje, E. \& Borthwick, K. (2021). Researching massive open online courses for language teaching
} and learning. ReCALL 33(2): 107-110. https://doi.org/10.1017/S0958344021000094 
LMOOCs are the fact that they make quality language learning resources available for free, and that they redefine teacher and learner roles, making the learning process more student centred. As for challenges, some authors have noted that using MOOC platforms may make language learning a less enjoyable and/or productive experience, especially in encouraging oral production. In addition, the fact that language learning is skill based and entails a great deal of practice and interaction does not make it easy for learners trying to complete an LMOOC.

Although LMOOC research is an emergent field of study, with the first scholarly publications dating back to only 2014, it is an expanding one. The following research trends or directions for LMOOC research have been identified (Sallam et al., 2020): (1) conceptualisation of LMOOCs and their distinctive features, (2) attempts to find the most suitable model for language teaching and learning beyond the xMOOC/cMOOC dichotomy, ${ }^{1}(3)$ suitability of LMOOCs for languages for specific purposes courses, (4) focus on the learners and their motivation and experience throughout the course, (5) reflection on the new role of the teacher, (6) instructional design and how it affects participants' learning and possible attrition, and (7) the importance of social learning in LMOOCs. The number and depth of these identified trends is an indication of the interest and opportunity in the field of LMOOCs.

This special issue aims to offer a timely snapshot of the emergent international research landscape regarding LMOOCs. We include submissions from authors based in China, Iceland, Ireland, Spain, and the United Kingdom discussing MOOCs for widely taught languages such as English and Spanish, as well as less widely taught languages (Irish and Icelandic). This geographical and linguistic diversity reflects the promise of MOOCs to support and develop language knowledge among dispersed communities of learners (Borthwick, 2020). The papers presented in this issue have a common theme: they all seek to understand aspects of quality in the design and delivery of MOOCs by focusing on different dimensions of the MOOC learner experience. MOOCs are inherently informal, learner centred, and learner driven: a MOOC learner decides how, when, and how much to engage with a course, and it is learner engagement and activity that breathes life into a MOOC through social and peer learning. The nature of MOOCs - and of learners' relationships to them - reminds us of the importance of understanding MOOC participants in the same way that Ushioda (2011) argues that we should understand language learners; that is, holistically as "'people' (rather than types of learner) with uniquely individual personalities, histories, motives, interests and identities" (p. 204). This seems highly appropriate when investigating language learner experiences of informal, open, self-directed courses of learning. The articles in this issue address and explore this complexity and diversity in learner experience, challenging our assumptions about LMOOCs and their participants.

We open this special issue with a paper by Conchúr Mac Lochlainn, Mairéad Nic Giolla Mhichíl, and Elaine Beirne, who investigate participation and learner behaviour in an Irish language MOOC. They set the scene both for the special issue and for their research in a paper arguing for the importance of conceiving the LMOOC learner as an individual operating within a social, cultural, and personal context. Their argument arises from their study that uses mixed methods to explore typical patterns of behaviour among course participants alongside learners' own reflections upon the reasons for their behaviour. The authors' study reveals wide variation in learner behaviour, and this leads them to argue for the need for further detailed qualitative investigation to unearth a true picture of LMOOC learner needs. The authors' findings challenge our acceptance of the value of MOOCs (to learners) as virtual communities of practice by revealing findings that demonstrate individual, silent engagement that is nonetheless highly satisfactory (to learners). The authors also uncover interesting insights into how older learners participated in their LMOOC, suggesting that this demographic group merits further study. This paper forcefully reminds us of the need to remember the individual behind the "LMOOC learner" and in doing so

\footnotetext{
${ }^{1}$ cMOOCs, or connectivist MOOCs, do not have a centralised core of content but a networked one. In contrast, xMOOCs run on a single online platform and are more similar in structure to traditional online courses.
} 
will give MOOC designers pause for reflection on possible assumptions that underpin the design of open online courses for language learning.

The paper by Kolbrún Friðriksdóttir also seeks to understand key aspects of effective LMOOC design through the lens of learner experience. In the study, she explores whether specific factors related to course content, design, and structure had an impact on learner retention and engagement in an LMOOC for learning Icelandic. She analyses technical tracking data on learner engagement with course content and matches it to responses to a learner survey in an attempt to identify the reality of participant engagement alongside participants' perceptions of engagement and their stated motivations. She included in her study learners who had quit the course before completing - a demographic that is often difficult for researchers to reach and engage with. Her findings suggest that course design and structure do have an impact on engagement and motivation. As with our first paper, her results exemplify how the complexity of LMOOC learners' lives often impacts on their ability to engage and learn - but she also discovers learners' tenacity, personal dedication, and motivation to complete their language learning over time.

Zsuzsanna Bárkányi's paper explores the links between motivation, computer-mediated communication, and open learning in a MOOC to investigate whether the online MOOC space is an environment that reduces foreign language speaking anxiety (FLSA). She suggests that one might assume that learners who are sufficiently motivated to voluntarily take an open MOOC, in an online "shielded" environment, might feel less FLSA than when learning in a face-to-face environment. Zsuzsanna's study challenges this assumption. Her detailed study analyses a large amount of data from four Spanish language MOOCs, including pre- and post-course surveys and in-course form posts. She seeks to understand how MOOC learners' motivations relate to FLSA, whether their self-efficacy beliefs alter over the course of their study, and whether there is a correlation between motivation, self-efficacy beliefs, and FLSA. Her findings show that anxiety levels throughout the MOOCs remained stable, even while self-efficacy beliefs improved. She concludes that FLSA is a feature of language learning in all environments and should be considered in course design and planning. This reminds us again of the importance of recognising the individual in the language learning process and also the specific nature of language learning in our CALL designs.

The nature of language learning and the needs of online language learners are ideas present in the paper by Christine Appel and Joan-Tomàs Pujolà, who address an aspect of language learning that is often challenging in open, large-scale online courses - that of enabling interactive speaking practice. They discuss the creation and subsequent iterations of an LMOOC that incorporates elements of speaking interaction practice: "eTandemMOOC". There is much for course designers to learn from their design-based approach, which provides a solid foundation to develop a course that has since evolved in response to learner feedback, educator experience, and engagement data. What didn't work is as useful here as what did, and their simultaneous design/research approach has enabled their course to develop and achieve sustained engagement and positive learner evaluations over time.

Listening and responding to LMOOC learners' perspectives and impressions is at the heart of our final paper by Rong Luo and Zixuan Ye. Their paper takes on the difficult task of identifying quality criteria for LMOOCs and suggesting a framework for LMOOC designers to work with. They deliberately choose to work with learner perspectives as the basis of their quality framework, using grounded theory methods to analyse evaluative comments made by learners taking part in 10 popular English as a second language (ESL) MOOCs. The research focuses exclusively on learner perceptions of what works well in an LMOOC and gives useful insights into the aspects of course design and delivery that their participants found effective. The strong focus on learner perceptions of quality and value across a number of different ESL MOOCs suggests some common features related to technical functionality, pedagogical course and task design, and course delivery to consider in LMOOC design.

We would like to thank our authors for their contributions to this special issue. We received a large number of very high-quality submissions and unfortunately could not include them all; 
however, this reflects the range and quality of research currently underway in the area of LMOOCs. The papers included here inform and advance the field of LMOOC study. Each contribution points to new possible avenues of investigation, and we hope that this special issue will stimulate both the creation of more LMOOCs and further empirical and theoretical research to inform and develop this exciting, emerging field.

Acknowledgements. The guest editors wish to thank colleagues who contributed to this special issue by submitting or reviewing papers. We also extend our thanks to Sylvie Thouësny and Alex Boulton for their advice and support during the preparation of this issue.

\section{References}

Bárcena, E. \& Martín-Monje, E. (2014) Introduction: Language MOOCs: An emerging field. In Martín Monje, E. \& Bárcena, E. (eds.), Language MOOCs: Providing learning, transcending boundaries. Berlin: De Gruyter Open, 1-15. https://doi.org/10. 2478/9783110420067.1

Bárcena, E., Read, T., Martín-Monje, E. \& Castrillo, M. D. (2014) Analysing student participation in foreign language MOOCs: A case study. In Cress, U. \& Delgado, C. (eds.), EMOOCs 2014: Proceedings of the European MOOCs Stakeholders Summit 2014. Mons, Belgium: P.A.U. Education, 11-17.

Borthwick, K. (2020) Treasuring and preserving languages: How the inclusive design in MOOCs might help. In Plutino, A., Borthwick, K. \& Corradini, E. (eds.), Innovative language teaching and learning at university: Treasuring languages. Dublin: Research-publishing.net, 5-12. https://doi.org/10.14705/rpnet.2020.40.1059

Comas-Quinn, A. \& Borthwick, K. (2015) Sharing: Open educational resources for language teachers. In Hampel, R. \& Stickler, U. (eds.), Developing online language teaching: Research-based pedagogies and practices. Basingstoke: Palgrave Macmillan, 96-112. https://doi.org/10.1057/9781137412263_7

Gillespie, J. (2020) CALL research: Where are we now? ReCALL, 32(2): 127-144. https://doi.org/10.1017/S0958344020000051

Gimeno-Sanz, A. (2016) Moving a step further from "integrative CALL": What's to come? Computer Assisted Language Learning, 29(6): 1102-1115. https://doi.org/10.1080/09588221.2015.1103271

Godwin-Jones, R. (2014) Global reach and local practice: The promise of MOOCs. Language Learning \& Technology, 18(3): 5-15. https://doi.org/10125/44377

Jitpaisarnwattana, N., Reinders, H. \& Darasawang, P. (2019) Language MOOCs: An expanding field. Technology in Language Teaching \& Learning, 1(1): 21-32. https://doi.org/10.29140/tltl.v1n1.142

Martín-Monje, E. \& Bárcena, E. (eds.) (2014) Language MOOCs: Providing learning, transcending boundaries. Berlin: De Gruyter Open. https://doi.org/10.2478/9783110420067

Mazoue, J. (2013) The MOOC model: Challenging traditional education. https://er.educause.edu/articles/2013/1/the-moocmodel-challenging-traditional-education

Panagiotidis, P. (2019) MOOCs for language learning: Reality and prospects. In Graziano, K. (ed.), Proceedings of the Society for Information Technology and Teacher Education International Conference. Las Vegas: Association for the Advancement of Computing in Education (AACE), 540-546.

Sallam, M. H., Martín-Monje, E. \& Li, Y. (2020) Research trends in language MOOC studies: A systematic review of the published literature (2012-2018). Computer Assisted Language Learning. Advance online publication. https://doi.org/10. $1080 / 09588221.2020 .1744668$

Shah, D. (2020) The second year of the MOOC: A review of MOOC stats and trends in 2020. https://www.classcentral.com/ report/the-second-year-of-the-mooc

Ushioda, E. (2011) Language learning motivation, self and identity: Current theoretical perspectives. Computer Assisted Language Learning, 24(3): 199-210. https://doi.org/10.1080/09588221.2010.538701 